\title{
RESEARCH
}

\section{Exploring Experiences of UK Pharmacy Graduates in Dealing With Professional Dilemmas in Transition to Practice}

\author{
Maria D. Allinson, PharmD, Patricia E. Black, EdD, Simon J. White, PhD \\ Keele University, School of Pharmacy and Bioengineering, Staffordshire, United Kingdom
}

Corresponding Author: Maria D. Allinson, Keele University, School of Pharmacy and Bioengineering, 124a Hornbeam Building, Keele, Staffordshire, UK. Tel: +44-01782-734133. Email: m.d.allinson@ keele.ac.uk

Submitted March 16, 2021; accepted August 22, 2021; ePublished September 2021

Objective. For many UK pharmacy students there are minimal opportunities to learn, or be exposed to, different ways of dealing with ethical and professional dilemmas in real life practice during undergraduate education. This study aimed to explore the experiences of graduates during their pre-registration year and early practice (up to two years post qualification) on their perceived preparedness to make professional decisions when faced with problems or dilemmas once in practice.

Method. Semi-structured interviews were undertaken with pre-registration trainees and early careers pharmacists (up to two years qualified). Interviews were transcribed verbatim and analysed thematically using the Framework Approach. Ethical approval was obtained to undertake the study.

Results. Eighteen interviews were conducted: nine pre-registration trainees and nine qualified pharmacists. Four key themes emerged: continued learning in practice; exposure to role-modelling; moral courage; and stress and moral distress.

Conclusion. This study found that there is a perceived need for further support, challenge and positive role-modelling to help pre-registration trainees and early career pharmacists continue to develop their ethical and professional decision-making skills in the practice setting. The level and quality of support reported was variable, and there was a reliance on informal networks of peer support in many cases. This study suggests a need to raise awareness among pre-registration tutors and line managers to improve and increase support in this area.

Keywords: transition, pharmacy, early practice, role models, peer support

\section{INTRODUCTION}

In the UK, upon completion of their Masters of Pharmacy (MPharm) degree, pharmacy graduates undertake a year-long pre-registration training period (internship), most often within a single sector (usually hospital or community pharmacy). In contrast to the US system, the student has the responsibility of finding their own preregistration placement, and following graduation, the university has no control over the final year of training (preregistration year). Pre-registration tutors support pre-registration trainees in this period of their training. Pharmacists who wish to become pre-registration tutors must have been practising within their chosen field for at least three years. The tutor must be assured that their trainee meets required competencies in various standardised tasks before declaring them fit to practise. These competencies are stipulated by the UK General Pharmaceutical Council (GPhC), which is the professional regulatory body/licensing board in the UK. In addition, students must pass a national pre-registration exam (equivalent to a licensure exam in the USA) at the end of their pre-registration year in order to finally become registered as a pharmacist with the UK GPhC. ${ }^{1}$

Unlike many other health care fields, the UK pharmacy undergraduate course is funded as a science course with no clinical supplement for extended placement opportunities. As a result, there are often minimal opportunities for pharmacy students to learn, or be exposed to, different ways of dealing with ethical and professional dilemmas in real life practice. Siegler recommended that teaching ethics was reinforced by integrating it into medical clerkships (equivalent to placement opportunities) so students could observe ethical dilemmas in context and the ethical behaviour and professional conduct of experienced role models. ${ }^{2}$ Although individual Schools of Pharmacy provide opportunities of experiential learning, the amount of training can vary widely across institutions. ${ }^{3}$ This means that there is an onus on pre-registration tutors to ensure that their trainees further develop ethical and professional decisionmaking skills during their pre-registration year.

Once qualification is achieved, those early career pharmacists who practice in hospital pharmacy work within teams and can generally call on others for advice when faced with professional dilemmas. Those working in community pharmacy, however, are often solely responsible for the running of the pharmacy. Magola et al. found that novice community pharmacists newly transitioning into practice were faced with many stress-inducing challenges, with professional decision-making reported to be their greatest challenge in early practice. ${ }^{4}$ 
At Keele University School of Pharmacy and Bioengineering (SPhaB) in the UK, a study was undertaken to explore the experiences of graduates during their pre-registration year and early practice (up to two years post qualification). Specifically, views were sought on their perceived preparedness to make professional decisions when faced with problems or dilemmas in practice. This was part of a larger project studying the impact of teaching ethics and professional decision-making in the MPharm undergraduate degree.

\section{METHODS}

A qualitative approach was chosen to explore the in-depth views of interviewees. Interviews were favoured over focus groups as sensitive issues could potentially be discussed. All UK-based alumni from Keele University who were either pre-registration trainees or early career pharmacists (up to two years qualified) were invited to participate, either via a question at the end of a survey, or (for a proportion of pre-registration trainees) during a final year undergraduate teaching session. The aim was to achieve a purposive sample with a mix of male and female interviewees, both trainees and early career pharmacists, of varying ethnicities, working in hospital and community pharmacy. Interviews were conducted between May and June 2015, and also between January and March 2016, at times and places convenient to the interviewees. This enabled data saturation to be reached, whereby additional data did not reveal any new insights or information related to the broad topics of interest in the interview guide. ${ }^{5}$

An interview schedule was developed based on a literature review and the aims of the study (See Appendix 1). It addressed interviewees' views on teaching and learning ethics and professional decision-making at Keele University SPhaB (not reported here) and their views on transitioning to professional practice. The schedule was assessed by an experienced researcher for face validity and some rephrasing was made to avoid leading questions. ${ }^{6}$ The interview schedule was used as a guide to ensure all topics were covered, but was not adhered to rigidly so that conversation could flow freely. Qualitative interviews are an iterative process; the first three interviews yielded rich data with no substantive changes made to questions, so these were included in the final analysis.

Participant information sheets were emailed in advance and, once arranged, interviewees were invited to ask any further questions prior to the interview commencing. A consent form was signed before starting, the interview was audio-recorded. Interviews were transcribed verbatim and analysed thematically using the Framework Approach. ${ }^{7}$ This involved seven stages: transcription, familiarisation, coding, developing a framework, applying a framework, charting the data and interpreting the data. ${ }^{8} \mathrm{MA}$ and PB independently coded the first three interviews. A coding framework was agreed upon and was subsequently applied to the rest of the transcripts. Of note, the aim of the project was not specifically to compare pre-registration trainees to early career pharmacists, but to gauge views from alumni who have not long graduated, therefore all 18 participants were analysed together. Where the pre-registration trainees and pharmacists have clearly differed, this is reported below. Ethical approval for the study was received from Keele University Research Ethics Committee (Reference ERP322).

\section{RESULTS}

Eighteen semi-structured interviews were conducted, ranging from 50 minutes to 2 hours, with eighteen interviewees. There were nine pharmacists and nine pre-registration trainees, 13 of which were female, 10 were Caucasian and 13 were working in community pharmacy, with 5 based in hospital pharmacy. Four main themes emerged: continued learning in practice; exposure to role-modelling; moral courage; and stress and moral distress. These are discussed below, with additional exemplar quotes presented in Table 1.

With the myriad of professional and ethical dilemmas that could potentially occur in practice, interviewees acknowledged that it would be impossible to prepare fully for every eventuality, and that there were limitations on what could be achieved at undergraduate level. Interviewees, therefore, recognised a need for ongoing support around professional decision-making, particularly during the pre-registration year and when first qualified. They reported, however, that they did continue to learn from others during this time in practice. Interviewees reported learning from a range of people within their organisation, including pre-registration tutors, senior staff (managers and superintendents) and also by accessing support services, for example, a governance department within their organisation's Head Office.

Four pre-registration trainees and two pharmacists reported that they referred to their pre-registration tutor as a source of advice, usually to discuss and reflect on problems. Pre-registration trainee 1 remembered in a general sense asking for a more in-depth analysis of her pre-registration tutor's decision-making, stating: "I've asked him about things, sort of saying, 'how do you make decisions? What's your rationale?' (PRT1). Not all interviewees had such indepth interactions however and reported that they had simply learned through observation. Pre-registration trainee 7 described how he learned to form his own way of dealing with problems after working with a range of staff, including pharmacy 'locums' who are contracted to provide temporary cover for the regular pharmacist. Through observation, he was able to identify strategies that worked well for other pharmacists faced with difficult dilemmas in practice.

Although interviewees reported that the majority of further learning around decision-making tended to be learning from those around them, they also identified their peers as a valuable source of support. Four interviewees reported contacting former friends from university for advice via WhatsApp messaging groups, 
either whilst in the midst of a difficult dilemma, or when reflecting on a past problem. Peer supervision was also reported to be a valuable learning tool. Pharmacist 9 reported participating in formalised peer supervision sessions within his organisation, finding that peers were much more confident to talk about dilemmas among themselves rather than with senior staff. Similarly, during monthly preregistration development days, preregistration trainees had the opportunity to discuss problems together, facilitated by a pharmacist.

Interviewees were not asked specifically about role-models, but referred to having observed negative rolemodels in practice three times as often as positive ones. Positive role models were perceived to be good communicators, respectful to colleagues, and able to provide good advice. Some referred to their pre-registration tutor as a helpful, positive influence and aspired to be like them, but not all. There were many variations of negative rolemodels observed in practice. Interviewees reported an unprofessional attitude and behaviour in some pharmacists towards both colleagues and patients, for example lack of compassion or lack of care towards the role itself. Illegal practices were referred to, for example Pre-registration trainee 6 was shocked to see controlled drugs being dispensed without a valid prescription. Another aspect of negative role-modelling related to pharmacists either not challenging a doctor or backing down too easily. Pre-registration trainee 2 perceived even experienced pharmacists to lack confidence in their role, whilst pharmacists with poor knowledge of clinical or legal issues were also reported. When faced with poor practice or difficult decisions, it is important that trainees and pharmacists have the courage to do the right thing. Moral courage is the courage to speak up or act for what you believe to be morally right, in the face of fear of potential consequences for doing so. ${ }^{9}$ A sign of preparedness for practice among the interviewees was a willingness to challenge rules and regulations to ensure that the best interests of patients were met. Although they understood right from wrong in terms of the law, pharmacists in this study were more willing than trainees to make choices contrary to the law which they felt were morally right. In doing so they were demonstrating moral courage as they were leaving themselves vulnerable to retribution, either from the GPhC or their employing organisation (or both). Courage was also demonstrated by ensuring work was undertaken within legal boundaries in pharmacies where poor practice was the cultural norm. For example, whilst working as a locum pharmacist, Pharmacist 6 had the courage to stand up to an aggressive patient and dispensary staff who were pressurising her to dispense an unsigned prescription.

Not all interviewees, however, appeared to feel that they could challenge all issues relating to poor practice. This was observed among pre-registration trainees in particular, where four of the nine trainees reported that they would not challenge a qualified pharmacist. Pre-registration trainee 6 , for example, found it difficult as a trainee to challenge experienced pharmacists who were not following the legal requirements for controlled drug register entries. He appeared to set his own standards, though, so despite not challenging pharmacists who made legal errors (and he refused to follow suit), he stated that he would challenge decisions that affected patient care.

Moral distress has been defined as 'the experience of psychological distress that results from engaging in, or failing to prevent, decisions or behaviours that transgress, or come to transgress, personally held moral or ethical beliefs. ${ }^{10}$ There were a few situations described by interviewees that could have potentially contributed to moral distress, including inequity of service and dilemmas around commercial concerns. For example, Pharmacist 2 was left feeling "conflicted" when asked by a senior manager to falsify in-house records in order for the pharmacy to meet a weekly MUR (Medicines Use Review [consultation on adherence of medicines]) target. She agreed, justifying her decision by stating that there was "... an honest intention to do them [the five MURs]". On reflection she felt that she "made the right decision for the shop", demonstrating company loyalty, but at what expense to her own moral values?

The examples given by interviewees of stressful feelings were, however, more often related to a fear of the possible consequences from breaking the law. They therefore acted in congruence with their personal moral values but experienced stress as a result of doing so. Interviewees worried about the potential consequences that a poor decision might have on their career. They articulated this by referring to a fear of legal consequences, regulatory sanctions by the $\mathrm{GPhC}$, or retribution by the employing company. Legal and procedural concerns were evident throughout the interviews but, in most cases, were balanced with a caring, patient-centred approach.

\section{DISCUSSION}

This study has found that, although interviewees reported benefiting from their undergraduate education around ethical and professional decision-making, they reported that they required further support when transitioning to practice. They talked about learning mostly from observing staff around them, and sometimes through ethical or professional discourse; this was not, however, the norm. They learned from positive rolemodels, but also learned what not to do from observing negative role-models. Interviewees reported valuing peer supervision, as well as supporting and learning from each other through informal networks. When faced with professional and/or ethical dilemmas in practice, the pharmacists interviewed tended to demonstrate moral courage, whereas pre-registration trainees, probably unsurprisingly, were more reticent. Most interviewees reported feelings of stress related to the potential consequences of their decisions, particularly when they were willing to break the law. They still, however, reported a person-centred and caring approach towards patients. 
Countries where the university has input to the experiential learning experience post-graduation (such as the USA), may have more opportunity to address these issues pre-licensure. Similarly the UK will align more closely with the USA system when newly introduced changes to the UK degree format come into force. ${ }^{11}$

The 'hidden curriculum' is a socialisation process through which values and norms are transmitted; these can often be at variance with what is taught explicitly. ${ }^{12}$ Most values, attitudes, beliefs and related behaviours are learned implicitly through this 'hidden curriculum' rather than through explicit formal teaching, in part by observing role models and their positive and negative attributes. Role models can, therefore, play a vital part in preparing pharmacy students and pre-registration trainees for practice. In fact, it has been argued that role-modelling is highly influential and the most important strategy for improving professionalism among pharmacy students. ${ }^{13}$ Observing positive role models was recognised in this study as a learning opportunity on how to deal with dilemmas in practice. According to Bandura's Self-Efficacy Theory (1982), vicarious experiences of observing role models succeed in their endeavours raises our own self-belief that we too can succeed.$^{14}$ Having positive role models to learn from in practice, therefore, is important in supporting preregistration trainees and early career pharmacists to develop confidence and belief in their ability to make sound, justifiable ethical and professional decisions in practice.

Bandura also proposed that the most effective way to develop confidence (or 'self-efficacy') is to gain mastery of the task. ${ }^{14}$ The more opportunities individuals have to experience and cope effectively with dilemmas, the greater their self-belief will be that they can deal competently with future problems. In theory, therefore, those transitioning through pre-registration training and early practice would benefit from being challenged often (in a supportive environment). When considering the pre-registration training year, this would require the pre-registration tutor to undertake a proactive role in questioning, challenging and partaking in ethical discourse with their trainees around the professional dilemmas that they are being faced with. This study suggests that this in-depth interaction is not commonplace. There is scope therefore to raise awareness of this need among pre-registration tutors, and to support them in developing this aspect of their role. In addition, increasing placement duration and frequency during pharmacy undergraduate years should increase the opportunities for students to observe, or even experience, professional problems or 'dilemmas' in real life, and would benefit from seeing how they are resolved in practice.

Although pharmacy pre-registration tutors have been identified previously as strong role models, some tutors, and other experienced pharmacists, were associated with more negative connotations in this study. ${ }^{15}$ Negative role models have been identified across other health care professions too in both clinical and classroom settings. ${ }^{16.17}$ Recommendations to counteract potentially negative effects of the hidden curriculum have included having frank dialogue about real life experiences and the observed challenges to professional ideals. ${ }^{12}$ It has also been suggested that raising awareness of the positive and negative effects that role-modelling could have on an undergraduate students' own professional development could increase their resilience so that they are better prepared when faced with it in practice. ${ }^{18}$

Having the opportunity to discuss experiences of ethical and professional dilemmas was important to some interviewees, who reported learning from peers within their organisation, either formally or informally, by discussing the dilemmas that they had been exposed to. Social media has a positive role to play, as a platform for informal networks of support among trainees and early career pharmacists. Interviewees reported asking for advice and sharing their own experiences in this way, finding it a valuable tool. In the UK, some organised peer support networks are available. In theory, peer discussion provides an opportunity for deliberation on real life ethical cases, which is fundamental to developing skills in decision-making. ${ }^{19,20}$ This opportunity for peer discussion or 'peer supervision' forms the basis of a more formalised approach to developing person-centred care within some organisations. Known as Schwartz rounds, professionals in an organisation explore a workplace event such as a patient case, moderated by a trained facilitator. This allows staff time for reflection and sharing insights. Reported benefits have included increased empathy and greater ability among staff to handle sensitive issues. ${ }^{21}$ The use of a trained facilitator may not be a viable option for many, but the principles of reflecting and sharing insights can be applied in any setting.

Pharmacists and pre-registration trainees need to have the moral courage to deal effectively with, and act on, ethical or professional dilemmas in practice. The Nursing literature, in particular, has addressed the issue of moral courage in the workplace in recent years ${ }^{22,23}$ but literature relating specifically to moral courage among pharmacy professionals is limited. Moral courage relates to Rest's Four Component Model of Morality, a model of key components that are believed to be important for effective moral functioning in health professionals. ${ }^{24}$ It has, as its final element, moral character ie, being able to construct and have the moral courage to implement an action. Within this study, pharmacists reported experiences where they displayed the courage to do what was in the best interests of their patients, acting in accordance with their own moral values, despite being fearful of possible consequences. Most pre-registration trainees reported acting ethically themselves, although were less willing at times to put the patient before the law, or to speak up against observed poor practice. This reported difference was possibly due to preregistration trainees' limited experience in practice, combined with a lack of confidence in their own decision-making ability. Strategies have been proposed to develop moral courage, including cognitive strategies on how to deal with 
highly emotive situations, and training in assertiveness and negotiation skills to cope with hostility or defensiveness in others; these could be included within Pharmacy undergraduate curricula. ${ }^{25}$

Although prevalent in Nursing literature since the 1980's, ${ }^{26}$ the concept of moral distress in Pharmacy was only introduced by Kalvemark et al. in $2004 .{ }^{27}$ Traditionally moral distress had been defined as the stress due to ethical dilemmas, thought to result from institutional constraints, but the definition is much broader now. ${ }^{28}$ Moral distress has been found to cause anger and anxiety initially, but longer-term has been associated with, among other symptoms, feelings of guilt, hopelessness, loss of confidence and self-esteem. ${ }^{29}$ It has also been linked to burnout and mooted as a reason for leaving a profession. In this study, fear of consequences of breaking the law, or distress caused by not breaking the law when it was deemed the most ethical option, was reported among early career pharmacists and pre-registration trainees alike. Some interviewees worried about the potential consequences that a poor decision might have on their future career. Similar findings have been reported by pharmacists in international studies. ${ }^{30,31}$ In the UK, Astbury and Gallagher measured levels of moral distress experienced among community pharmacists, and found that moral distress was reported to be more frequent and intense among newly qualified pharmacists when compared with their more experienced colleagues. ${ }^{32}$ Moral distress must be seen within the context of ethical dilemmas and not separate from them. ${ }^{33}$ This means that the focus should not solely be on the individual to be able to make a wellreasoned judgement. Organisational changes, for example, adequate staffing levels and the culture within the organisation may need to be addressed to create an environment that early career pharmacists and pre-registration trainees feel empowered within to take an ethical course of action.

A key message from this study is that interviewees reported the need for ongoing support around professional and ethical decision-making both during pre-registration year and early practice. This finding aligns with the study by Magola et al. which reported community pharmacists (qualified up to 3 years) find professional decision-making to be their greatest challenge, with many also lacking confidence. ${ }^{4}$ A requirement for further training of tutors undertaking experiential learning with undergraduate students in the UK has also been highlighted ${ }^{3}$; this training could include support for pharmacists to undertake ethical discourse with students regarding professional problems faced in practice.

This in-depth study provides rich, thick data on the experiences and views of a range of pre-registration and early careers pharmacists across the UK, in both hospital and community pharmacy. It is important to note that the opportunity to undertake experiential education varies between countries though. For example, in the USA, greater exposure to practice during the Doctor of Pharmacy degree may equate to greater exposure to professional dilemmas prior to qualification. As an insider researcher (MA) there was a potential for social desirability bias. ${ }^{34} \mathrm{~A}$ reflexive approach was therefore applied throughout. Being an insider researcher also had its benefits; being known and trusted by the interviewees allowed for sensitive subjects to be openly addressed. In this study only the views of pre-registration trainees and early career pharmacists were addressed. Future studies could garner views of pre-registration tutors and other staff on the capability of trainees and newly qualified pharmacists. Furthermore, studies could be undertaken to gain in-depth views of pre-registration tutors regarding their own perceived needs around developing professional decision-making skills in others.

\section{CONCLUSION}

This study has found that there is a perceived need for further support, challenge and positive role-modelling to help pre-registration trainees and early career pharmacists continue to develop their ethical and professional decision-making skills in the practice setting in the UK. The level and quality of support reported was variable, and there was a reliance on informal networks of peer support in many cases. This study suggests a need to raise awareness among pre-registration tutors and line managers to improve and increase support in this area; this could potentially require upskilling of experienced pharmacists on ethical discourse to fulfil this role.

\section{REFERENCES}

1. General Pharmaceutical Council. Pharmacist pre-registration training scheme. Accessed August 8, 2020. https://www.pharmacyregulation.org/education/pharmacist-pre-registration-training-scheme

2. Siegler M. Training doctors for professionalism: some lessons from teaching clinical medical ethics. Mt Sinai J Med. November 2002;69(6):404-409.

3. Jacob SA, Boyter A. Experiential learning in MPharm programmes: a survey of UK universities. Poster presented at: Pharmacy Education Conference; June 2019; Manchester.

4. Magola E, Willis SC, Schafheutle EI. Community pharmacists at transition to independent practice: isolated, unsupported, and stressed. Health Soc Care Comm. November, 2018;26(6):849-859.

https://doi.org/10.1111/hsc. 12596

5. Charmaz K. Constructing Grounded Theory. A Practical Guide Through Qualitative Analysis. Sage; 2006.

6. Sim J, Wright C. Research in Health Care: Concepts, Designs and Methods. Stanley Thornes; 2000.

7. Ritchie J, Lewis J, McNaughton Nicholls C, Ormston R. Qualitative research practice. $2^{\text {nd }}$ ed. Sage Publications Ltd: 2014. 
8. Gale NK, Heath G, Cameron E, Rashid S, Redwood S. Using the framework method for the analysis of qualitative data in multi-disciplinary health research, BMC Med Res Methodol. September 2013;13:117-24. Accessed August 8, 2020. http://www.biomedcentral.com/1471-2288/13/117

9. Kritek PB. Reflections on moral courage, Nurs Sci Quart. June 2017;30(3):218-222. https://doi.org/10.1177\%2F0894318417708420

10. Crane MF, Bayl-Smith P, Cartmill J. A recommendation for expanding the definition of moral distress experienced in the workplace. Aust N Z J Organ Psychol. 2013;6:e1

11. General Pharmaceutical Council. Standards for the initial education and training of pharmacists. January 2021. Accessed August 2021. https://www.pharmacyregulation.org/sites/default/files/document/standards-forthe-initial-education-and-training-of-pharmacists-january-2021.pdf

12. Mahood SC. Medical education. Beware the hidden curriculum, Can Fam Physician, September 2011;57:983985. Accessed August 8, 2020. https://www.ncbi.nlm.nih.gov/pmc/articles/PMC3173411/pdf/0570983.pdf

13. Hammer D. Improving student professionalism during experiential learning. Am J Pharm Edu. June 2006;70(3):59. https://dx.doi.org/10.5688\%2Faj700359

14. Bandura A. (1982) Self-efficacy mechanisms in human agency, Am Psychol. 1982;37:122-147. https://psycnet.apa.org/doi/10.1037/0003-066X.37.2.122

15. Jee SD, Schafheutle EI, Noyce PR. Exploring the process of professional socialisation and development during pharmacy pre-registration training in England. Int J Pharm Pract. August 2016;24:283-293. https://doi.org/10.1111/ijpp.12250

16. Baernstein A, Amies Oelschlager AME, Chang TA, Wenrich MD. Learning professionalism: perspectives of pre-clinical medical students, Acad Med. May 2009;84(5):574-581. https://doi.org/10.1097/acm.0b013e31819f5f60

17. Jack K, Hamshire C, Chambers A. The influence of role models in undergraduate nurse education. J Clin Nurs. December, 2017;26(23-24):4707-4715. https://doi.org/10.1111/jocn.13822

18. Hopkins L, Saciragic L, Kim J and Posner G. (2016) The hidden curriculum. Exposing the unintended lessons of medical education. Cureus. October 2016:8(10):e845. doi:10.7759/cureus.845

19. Habermas J. Moral Consciousness and Communicative Action. The MIT Press: 1990.

20. Freire P. Pedagogy of the Oppressed. Penguin Books: 1996.

21. The Health Foundation. Person-centred care made simple. What everyone should know about person-centred care. January 2016. Accessed August 8, 2020.

https://www.health.org.uk/sites/health/files/PersonCentredCareMadeSimple.pdf.

22. Gallagher A. Moral distress and moral courage in everyday nursing practice. Online J Issues Nurs. March 2011:16(2):1-8. Accessed August 8, 2020.

https://search.proquest.com/openview/5cc064b115db6db1505b3c2050c2251b/1 ?pqorigsite=gscholar \&cbl=43 860

23. Edmonson C. Moral Courage and the nurse leader. Online J Issues Nurs. September 2010:15(3):Manuscript 5. DOI: 10.3912/OJIN.Vol15No03Man05

24. Rest JR. (1983) Morality. In Mussen PH, ed. Manual of child psychology. 4th ed. Wiley;1983:495-555.

25. Lachman VD. Strategies Necessary for Moral Courage. Online J Issues Nurs. September 2010:15(3):Manuscript 3. DOI: 10.3912/OJIN.Vol15No03Man03

26. Jameton A. Nursing Practice the Ethical Issues. Prentice Hall Inc: 1984.

27. Kalvemark S, Hoglund AT, Hansson MG, Westerholm P, Arnetz B. Living with conflicts-ethical dilemmas and moral distress in the health care system. Social Science and Medicine. March 2004;58:1075-1084. https://doi.org/10.1016/S0277-9536(03)00279-X

28. Crane MF, Bayl-Smith P, Cartmill J. A Recommendation for Expanding the Definition of Moral Distress Experienced in the Workplace. Australas J Organ Psychol. October 2013;6:e1. doi:10.1017/orp.2013.1

29. Burston AS, Tuckett AG. Moral distress in nursing: contributing factors, outcomes and interventions, Nurs Ethics. May 2013;20(3):312-324. https://doi.org/10.1177\%2F0969733012462049

30. Hadad AM. Ethical problems in pharmacy practice: a survey of difficulty and incidence, Am J Pharm Educ. Spring 1991;55(1):1-6.

31. Chaar B, Brien J, Krass I. Professional ethics in pharmacy: the Australian experience. Int J Pharm Pract. September 2005;13(3):195-204. https://doi.org/10.1211/ijpp.13.3.0005

32. Astbury JL, Gallagher CT. Moral distress among community pharmacists: causes and achievable remedies. Res Soc Admin Pharm. March 2020;16(3):321-328 https://doi.org/10.1016/j.sapharm.2019.05.019

33. Kalvemark Sporrong S, Hoglund AT, Arnetz B. (2006) Measuring moral distress in pharmacy and clinical practice. Nurs Ethics. July 2006:13(4):416-427. https://doi.org/10.1191/0969733006ne880oa

34. Drake P, Heath L. Practitioner research at doctoral level: Developing coherent research methodologies. Routledge: 2011. 
Table 1. Themes, Sub-themes and Exemplar Quotes from Pharmacy Graduates Regarding Experiences of Dealing with Professional Dilemmas

\begin{tabular}{|c|c|c|}
\hline Theme & Sub-themes & Example quotes \\
\hline \multirow[t]{3}{*}{$\begin{array}{l}\text { Continued } \\
\text { Learning in } \\
\text { Practice }\end{array}$} & $\begin{array}{l}\text { University setting cannot } \\
\text { prepare students fully }\end{array}$ & $\begin{array}{l}\text { "It [undergraduate teaching] did prepare us to a certain extent } \\
\text { but you never really know until you are actually in that } \\
\text { situation." (Pharmacist 5) }\end{array}$ \\
\hline & $\begin{array}{l}\text { Interviewees reported } \\
\text { learning from more } \\
\text { experienced pharmacists }\end{array}$ & $\begin{array}{l}\text { "I've seen a lot and seen how other people [locums, } \\
\text { technicians and dispensers] handle the issues. It's quite } \\
\text { interesting to see different people's perspectives on how to } \\
\text { deal with issues. That sort of makes me, not just copy what } \\
\text { they did, but take into account all the different approaches } \\
\text { you can do." (PRT*7) }\end{array}$ \\
\hline & $\begin{array}{l}\text { Interviewees reported } \\
\text { learning from peers, } \\
\text { sometimes through the } \\
\text { use of different media }\end{array}$ & $\begin{array}{l}\text { “...and we'd have a WhatsApp group on our iPhones and } \\
\text { we'd say "Oh I've seen this script. What do you think I should } \\
\text { do?” and we'd all give an opinion and we'd help each } \\
\text { other." (Pharmacist 1) }\end{array}$ \\
\hline
\end{tabular}

eg, WhatsApp

Messaging

Interviewees were willing to continue learning, for example, with peer supervision or facilitated discussion

“...the practitioner would usually ask, 'So how did everyone's week get on?' and [...] that sharing of stories you hear about their dilemmas, I think that's the best way [...] in my opinion that's how I learn." (PRT9)

Exposure to Lack of compassion

Poor Role-

"I don't think he seems that compassionate towards some of the patients [...] he's only been qualified about three

modelling

Lack of care towards the years..." (PRT6) role itself

“...to them [pharmacists] it's just a job that they turn up to, get through as quickly as possible and go [...] I think you've just got to have [...] desire to do the job." (Pharmacist 7)

Illegal practices

Poor clinical knowledge

“...they're really good pharmacists [...] why the hell are they doing this? Like this is completely illegal basically.” (PRT6)

“...when I first started [a two week placement] one of them [community pharmacist] said to me, 'you won't get much clinical from me' which I don't think is the right way to think about it." (PRT2)

Moral
Courage

Stress and Moral Distress

Worry associated with own decision-making and a fear of potential consequences. breaking the law but did not have the courage to speak up.
Acting in a patient's best interest, even if it meant

Observing poor practice

"...the patient is the most important thing so if you decide to go with the law, what's going to happen to that patient if they don't have their medicine?" (Pharmacist 1)

“...they're [pharmacists] a professional as well so if they want to do it [write CD entries] wrong they can do it wrong [...] but then if it's involving other people it's a bit different 'cos you need to step in." (PRT6)

“...it's a balancing act between what's the best for the patient and whether you're going to be called in front of a disciplinary committee for your actions and can you defend them, so it is stressful." (Pharmacist 7) 
Appendix 1 - Interview schedule

\section{Interview questions}

\section{Preparedness for practice}

- How prepared do you currently feel to deal with ethical dilemmas in practice?

- How does this compare with how you felt when you graduated and started your pre-reg year?

- In hindsight, how well or not do you feel your undergraduate years prepared you for dealing with ethical dilemmas in practice?

- How did you get to feel as prepared as you do now? 